\title{
An Analysis on Illumination Distribution and Residents' Perception in a Traditional Town for Streetlight Planning
}

\author{
Raheon Min, Nobuo Mishima, and Takayuki Fuchikami
}

\begin{abstract}
Streetlights are very necessary for security of residents at night and for night townscape also in traditional towns, although they were originally unequipped when the towns were built especially before the middle of the $19^{\text {th }}$ century. and their installations have been not well-considered for traditional values of the towns in Japan. To plan streetlights in a traditional town, fundamental issues and procedures including residents' perception should be clarified. This research attempts to reveal problems on a traditional area as a fundamental study for installation of streetlights in traditional towns.
\end{abstract}

Index Terms-Illumination, safety, streetlight, traditional town.

\section{INTRODUCTION}

\section{A. Background}

Many traditional towns also in Japan were built before streetlights were introduced and lots of streetlights have been installed after modern era. It needs to be considered carefully for historic towns when introducing something new that didn't exist before. Otherwise, it may unsuitable for preservation plan. Meanwhile, residents living in town need streetlights for security reasons.

In this research, target sites are Hamanaka-Machi Happongi-Shuku (hereafter, HMHS) area and Hamashozu-Machi Hamakanaya-Machi (hereafter, HMHM) area located in a traditional town called Hizenhamashuku, Kashima city, Saga prefecture, Japan(Fig.1). These two sites were selected as an important preservation district of traditional buildings in 2006.

Disaster and crime prevention is one of the crucial topics for resilience of historic towns. Mishima et al. study evacuation routes in a historic town [1]-[3]. In addition, there are many types of research about street light and crime prevention. First, some papers focus on the results of a coordinated program of research designed to evaluate the impact of street lighting improvements on crime and fear of crime [4]-[7]. Second, they analyzed illumination of street light using computer simulation programs to make a safe the city [8]-[10]. There are no studies on security street lights in a historic preservation town in Japan.

This study aims to reveal fundamental problems and procedures for installing streetlight in a traditional town by analysis of residents' range of activities and consciousness

\footnotetext{
Manuscript received January 2, 2018; revised May 2, 2018.

The authors are with the Department of Civil Engineering and Architecture, Graduate School of Science and Engineering, Saga University, Saga, Japan (e-mail: 17577019@edu.cc.saga-u.ac.jp, mishiman@cc.saga-u.ac.jp, fuchi@cc.saga-u.ac.jp).
}

about security based on distribution of streetlight.

\section{B. Housing and Living Environment Development Plan of Saga Prefecture}

Saga prefecture conducts street environment maintenance projects from 2016 to 2020 by the housing and living environment maintenance plan of Saga prefecture. This plan includes the installation of utility poles, beautification of roads, installation of security lights, and so on.

There will be installed 13 security lights on a street in front of Hizenhama station, 10 security lights on the Sakagura street in HMHS and 9 security lights in HMHM. And 9 old streetlights on the street in front of the station and 4 streetlights in places where there was nothing, so a total of 13 streetlights were already replaced with new security lights [11] (Fig. 2).

In 2008, Kashima City relocated the utility poles of Sakagura street which is the main street of HMHS to the behind of school and private houses for improving the scenery.
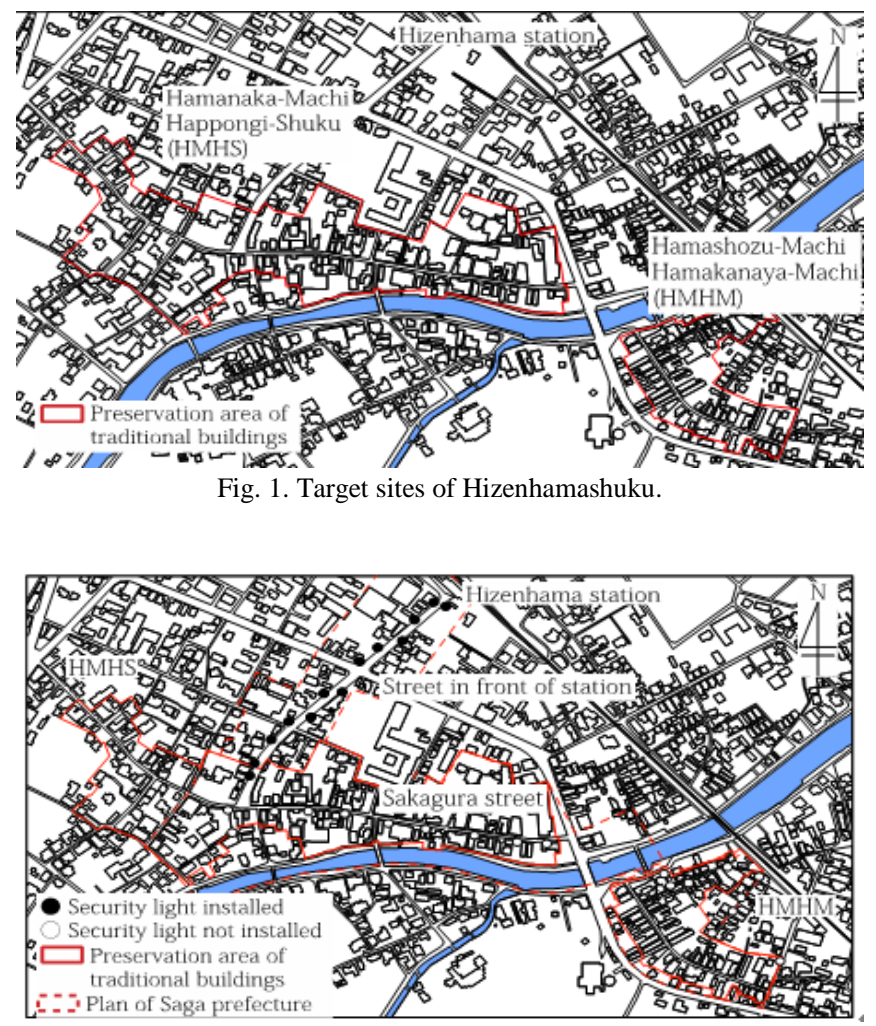

Fig. 2. Housing and living environment development plan of Saga prefecture.

\section{History of Introduction of Streetlights in Japan}

Starting to light the oil lamp an experimentally on the shore of Yokohama in September 1870 in Meiji era, streetlights were introduced in Japan. Two years later, in 
September 1872, a gas light that lighted in Yokohama was Japan's first streetlight. In 1874, a gas plant was built in Shibahamasaki-Cho, Tokyo, and a gas pipe was laid to Ginza so the gas lamp was lit between Ginza and Kyobashi. In March 25, 1878, the opening ceremony of the Central Telegraph Bureau was held at the Engineering University in Toranomon, Tokyo, and the arc lights were first ignited at the university hall. To commemorate this, March 25 is the anniversary of the Electricity. 4 Years later, in 1882, an electric streetlight with an arc lamp was lit in Tokyo, and it became visible to the public for the first time. In 1887, the lighting fixtures of Rokumeikan were changed into incandescent light, and they were the first street lamps produced by the electric bulb [12].

\section{Methods OF InVESTIGATION AND ANALYSIS}

Our investigation takes three steps to investigate the illumination of streetlights and residents' opinions about safety.

First, investigation survey is conducted especially on positions and numbers of the streetlights as well as on their shapes and colors taking photos to record both before and after the lights are turned on. Then, illumination and range of lights at 15 places are measured at intervals of 2 meters for each streetlight (Fig.3). This is an investigation to grasp the current situation of the streetlight.

Second, questionnaire surveys for the residents of the target sites are conducted through visiting house to house. The questions are about roads where they usually walk, streetlight, the fear of crimes, the presence or absence of security items and so on, marking the route (road) they usually go and they feel unsafe to walk on map.

Third, illumination distribution is analyzed using RELUX program which is an illumination simulation program to create an illumination distribution diagram. The types of the streetlight in the target sites cannot be specified because a date of product introduction does not remain in a government office. An illumination distribution diagram is, therefore, created with the streetlight of the most similar illumination in the RELUX program with reference the illumination of the streetlight examined by ourselves.

Compare these analyses to analyze the current problems in the region. Residents' opinions are used to grasp the current situation of streetlights that they are feeling.
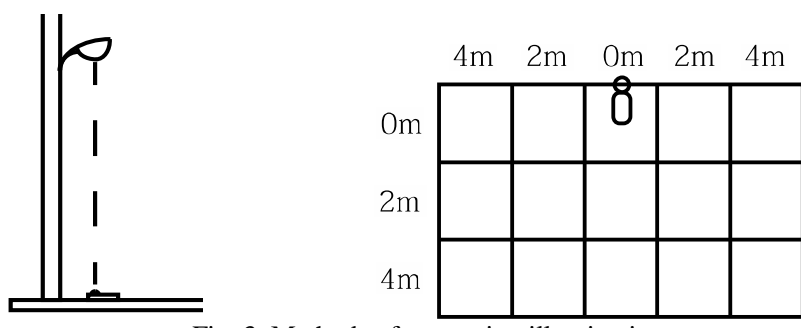

Fig. 3. Methods of measuring illumination.

\section{RESULTS AND ANALYSIS OF SURVEYS}

There were 49 streetlights in HMHS and 20 streetlights in HMHM. According to standards for road lighting for pedestrians based on Japanese Industrial Standards (JIS), the horizontal illumination, namely the average illumination on the road surface in the residential area of the road with low traffic volume must be $3 \mathrm{~lx}$ or more [13] (Table I). Yet, among these, 33 out of 49 streetlights in HMHS and 12 out of 20 streetlights in HMHM were less than 3 1x. Thus, $65 \%$ of the total streetlights were not enough for the Japanese Industry Standard, so these places need to be improved (Fig. 4).

TABLE I: ROAD LIGHTING FOR PEDESTRIANS BASED ON JIS

\begin{tabular}{|c|c|c|c|}
\hline \multirow{2}{*}{$\begin{array}{c}\text { Pedestrian Traffic } \\
\text { at Night }\end{array}$} & \multirow[b]{2}{*}{ Area } & \multicolumn{2}{|c|}{ Illumination (Ix) } \\
\hline & & $\begin{array}{c}\text { Horizontal Surface } \\
\text { Illuminance (1) }\end{array}$ & $\begin{array}{r}\text { Vertical Surface } \\
\text { Illuminance (2) } \\
\end{array}$ \\
\hline \multirow{2}{*}{ High-traffic Road } & Residential Area & 5 & 1 \\
\hline & Commercial Area & 20 & 4 \\
\hline \multirow{2}{*}{ Low-traffic Road } & Residential Area & 3 & 0.5 \\
\hline & Commercial Area & 10 & 2 \\
\hline
\end{tabular}

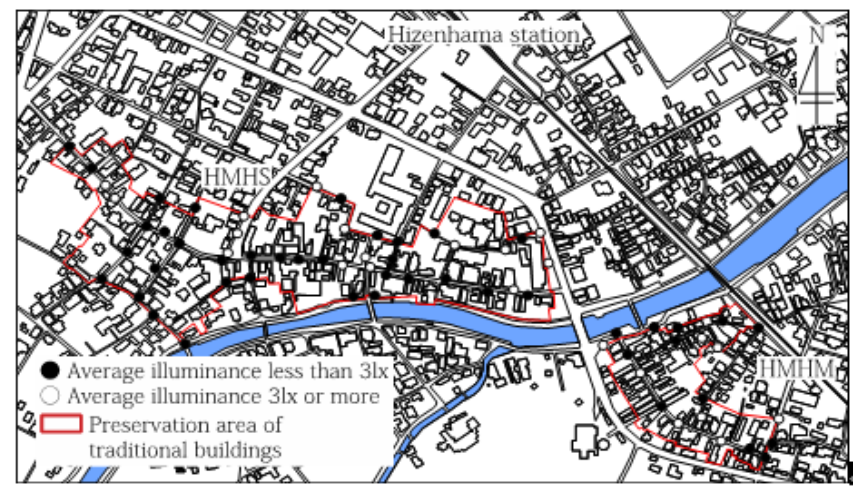

Fig. 4. Positions of streetlights and distribution of streetlights less than 3lx.

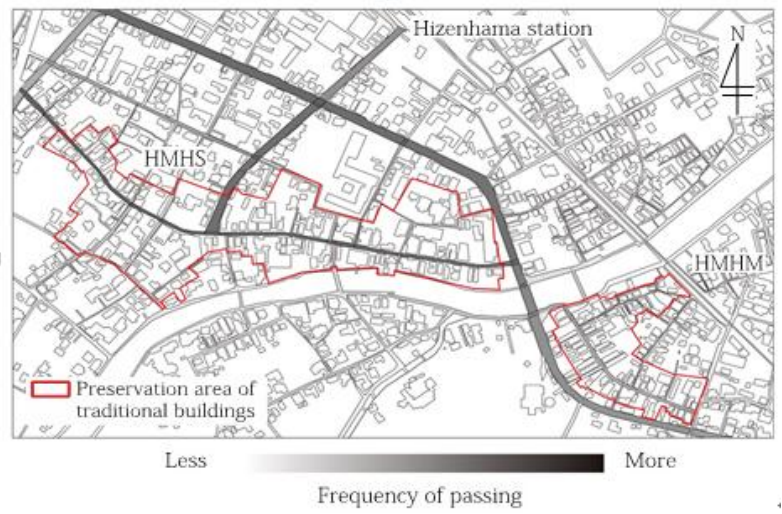

Fig. 5. Routes the residents go frequently.

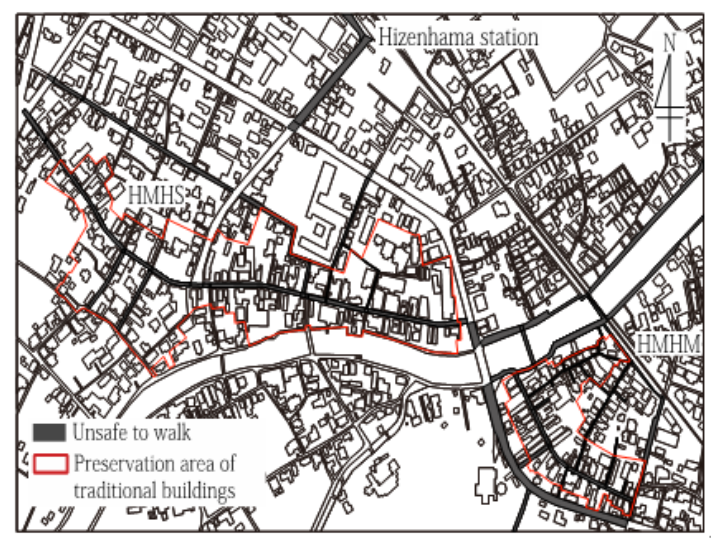

Fig. 6. Places where the residents feel unsafe to walk.

Also, according to the results of the questionnaire, it was found that the Sakagura street in HMHS was a route most 
found that the Sakagura street in HMHS was a route most people go frequently, but unsafe for residents to walk. From these results, we could find that the Sakagura street had too much traffic in spite of the narrow width with a waterway, as well as it was an important road in the area as connecting the HMHS and the HMHM (Fig.5-6).

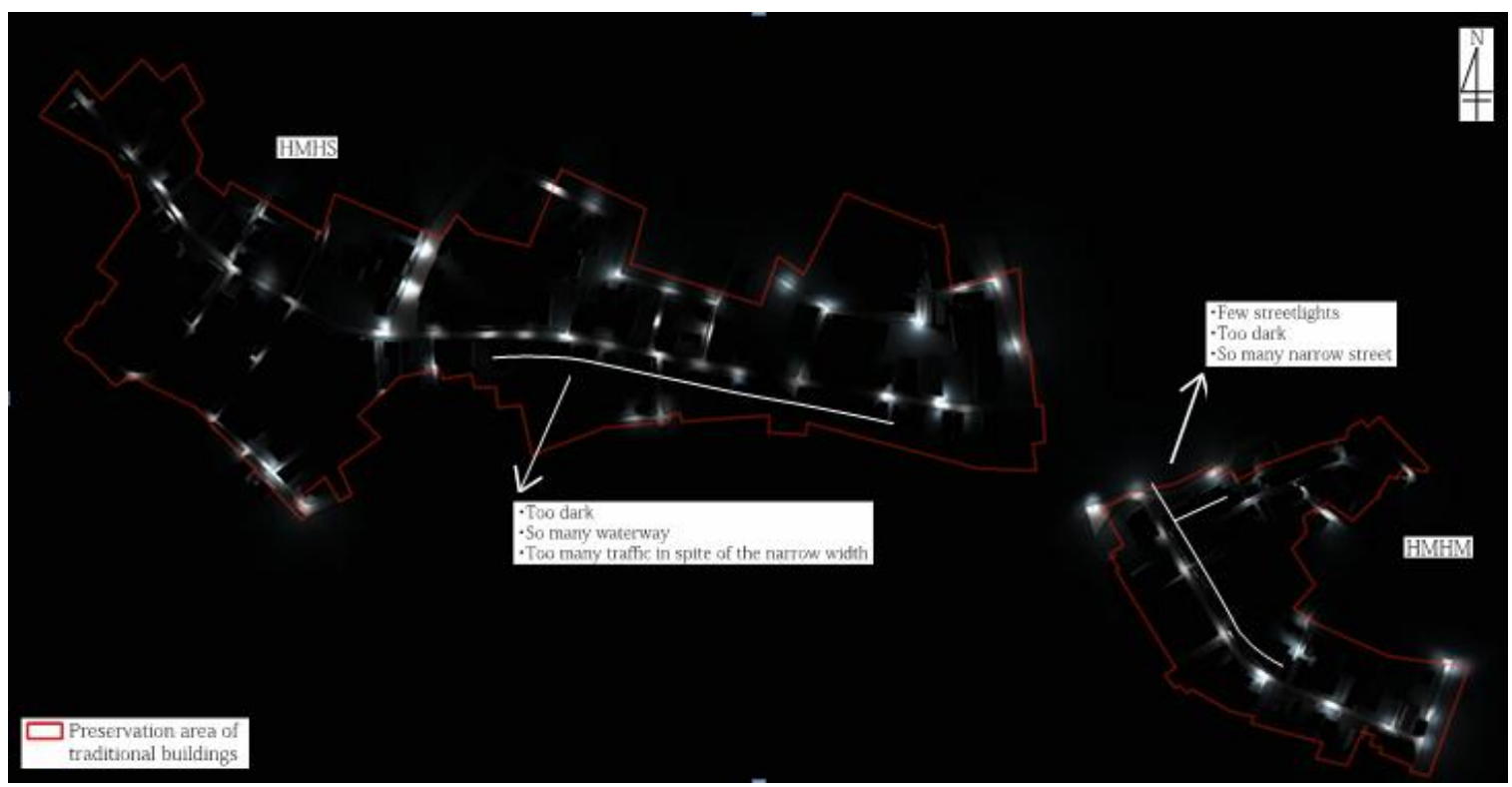

Fig. 7. Brightness of the area.

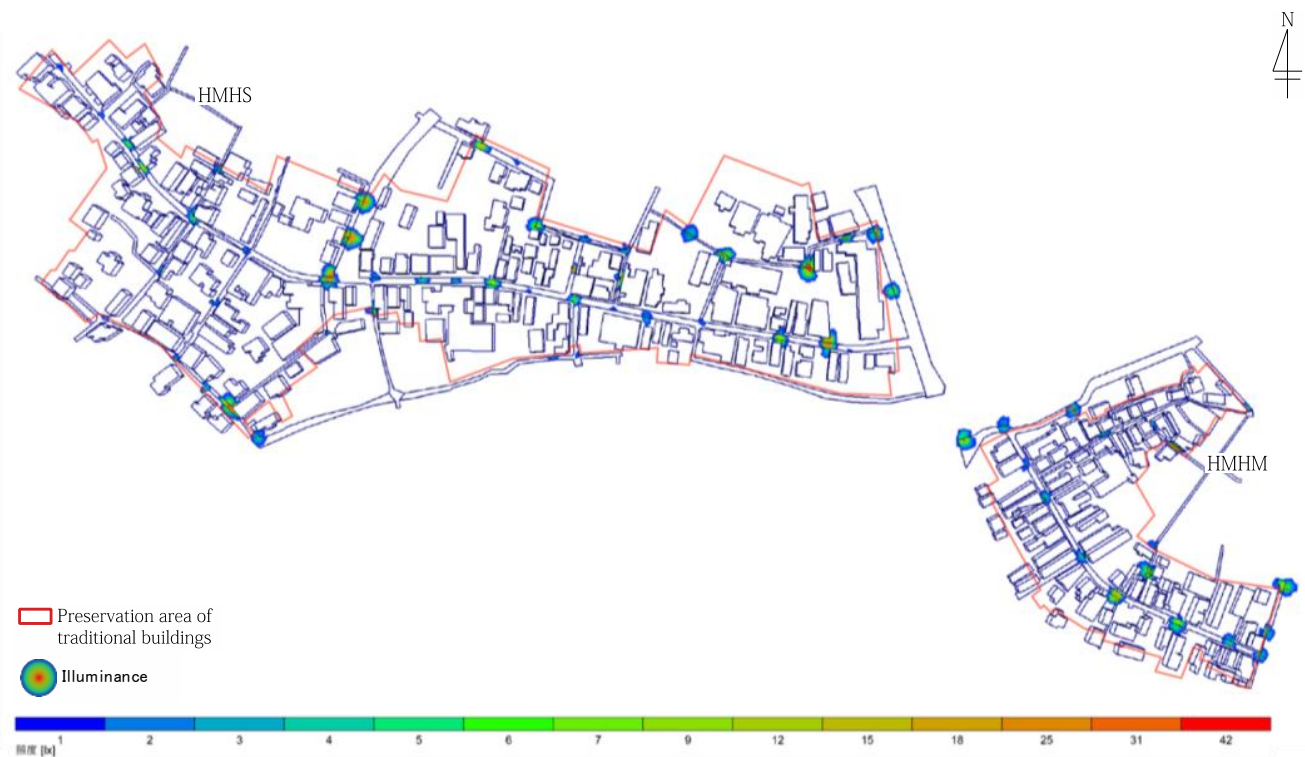

Fig. 8. Calculation result of illuminance of the area.

TABLE II: RESIDENT'S PERCEPTION ON THE STREETLIGHTS

\begin{tabular}{|c|c|l|l|}
\hline & Gender/Age & \multicolumn{1}{|c|}{ Opinions } & \multicolumn{1}{|c|}{ Keywords } \\
\hline 01 & Male/60s & There is no streetlight at the HamaShuku parking lot. & Streetlight \\
\hline 02 & Male/60s & I want to unified streetlights in accordance with the atmosphere of the town. & $\begin{array}{l}\text { Streetlight, } \\
\text { Atmosphere }\end{array}$ \\
\hline 03 & Male/60s & $\begin{array}{l}\text { I don't think there are enough streetlight for the historic town. It would be nice to have } \\
\text { unifying streetlights if it matches the atmosphere of the town. }\end{array}$ & $\begin{array}{l}\text { Streetlight, } \\
\text { Historic town, } \\
\text { Atmosphere }\end{array}$ \\
\hline 04 & Male/70s & I will expect a crime prevention, if new streetlights don't spoil the aesthetic of this area. & $\begin{array}{l}\text { Streetlight, } \\
\text { Aesthetic }\end{array}$ \\
\hline 05 & $\begin{array}{c}\text { Female/Over } \\
\text { than } 80 \mathrm{~s}\end{array}$ & $\begin{array}{l}\text { It is scary to walk outside where there are few streetlights especially narrow streets. I want } \\
\text { more streetlights. }\end{array}$ & $\begin{array}{l}\text { Streetlight, } \\
\text { Narrow Streets }\end{array}$ \\
\hline 06 & $\begin{array}{l}\text { Female/10s } \\
\text { streetlights. I didn't hear of any crime in Sakagura street but still feel anxious. I think there is } \\
\text { a lot of crime in dark place and afraid to go outside when it is dark, so it would be nice if there } \\
\text { are more streetlights. }\end{array}$ & $\begin{array}{l}\text { Streetlight, } \\
\text { Night, } \\
\text { Dark place }\end{array}$ \\
\hline
\end{tabular}




\begin{tabular}{|c|c|l|l|l|}
07 & Male/60s & $\begin{array}{l}\text { It will be dark at night, if the number of visitors increases. There is no disability in private } \\
\text { life. I hope residents, neighbors, and new residents can socialize more than ever before and } \\
\text { build a trust relationship from these results of the questionnaire survey. I think that if all the } \\
\text { people in this area greet with a smile to anyone, and if installed security streetlights make this } \\
\text { town safe and secure, then crime will be reduced. }\end{array}$ & $\begin{array}{l}\text { Streetlight, } \\
\text { Visitors, } \\
\text { Night, } \\
\text { Communication }\end{array}$ \\
\hline 08 & Female/70s & $\begin{array}{l}\text { In the HMHS, volunteers who lead the group in the heyday of Sakagura street, installed } \\
\text { stores as streetlights. And because the shops closed its shutters, electricity charges became a } \\
\text { burden. And changed streetlights to security lights, the cost of electricity charges became a } \\
\text { district burden. About 50 years, the electricity charges have been borne by local residents. } \\
\text { So, we want to change streetlights management in Sakagura street from district to city }\end{array}$ & $\begin{array}{l}\text { Streetlight, } \\
\text { Volunteers, } \\
\text { Management }\end{array}$ \\
\hline 09 & Male/60s & We need security camera at entrance of Garyugaoka park. & Security camera \\
\hline 10 & Female/40s & $\begin{array}{l}\text { Because the place to rely on is so far, so I think it would be nice to have some crime } \\
\text { prevention base here and there in this town. }\end{array}$ & $\begin{array}{l}\text { Crime prevention } \\
\text { base }\end{array}$ \\
\hline 11 & Female/60s & I feel anxious about the empty house. And they are decaying. & Empty house \\
\hline 12 & Male/70s & We need additional measures if visitors increase and go around at night. & Visitors, Night \\
\hline 13 & Male/60s & $\begin{array}{l}\text { I would like to make further improvements to the area while talking with people in this } \\
\text { district. }\end{array}$ & Communication \\
\hline
\end{tabular}

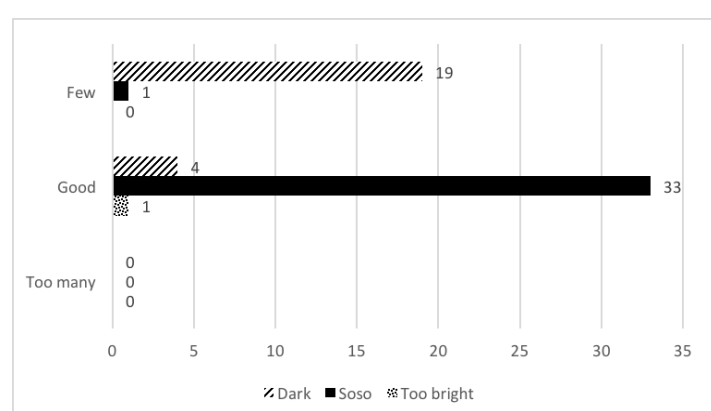

Fig. 9. Brightness and the number of streetlights.

The answers to the other items of the questionnaire survey on streetlights and residents' opinions were as follow (Table II). (58 people answered.)

First, it was about the brightness and the number of streetlights. They answered current streetlights are fine, but, many people answered there are few streetlights and very dark (Fig. 9).

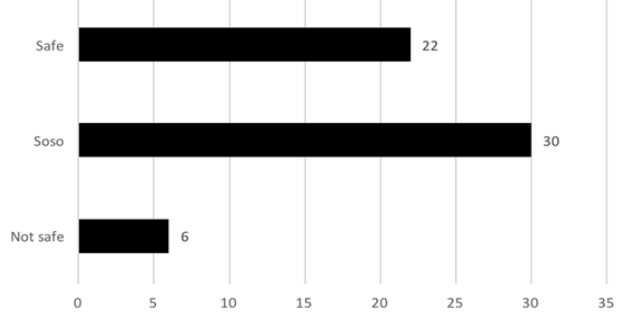

Fig. 10. Perception of residents on safeness in the area.

Second, it was about whether you feel safe or not in this town (Fig. 10). There were opinions from those who answered that they feel safe: 'Because people who live here are acquainted with each other.' and 'Because of the security of the town.'. There were opinions from those who answered that they feel normal: 'It may be a little dangerous because there are few people in the alley.', 'There were a crime a while ago.', 'Because sometimes I feel anxious when tourist came here.' and 'There are so many vacant houses.'. Finally, there were opinions from those who answered that they feel unsafe: 'Because so many houses are not locked. (Especially elderly people don't lock the door, so I think they are defenseless.)', 'I am scared of the night because there are few streetlights' and 'I think it is important to protect the aesthetic of the town (street), but it is dark at night so I think it is necessary to increase the streetlights.'.

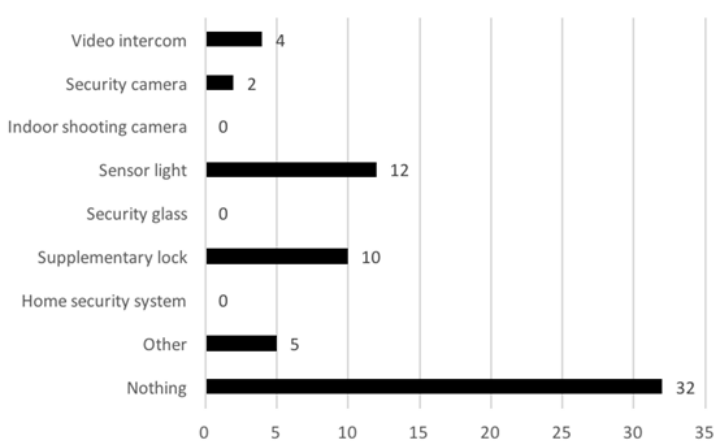

Fig. 11. The security items or systems they are using in house.

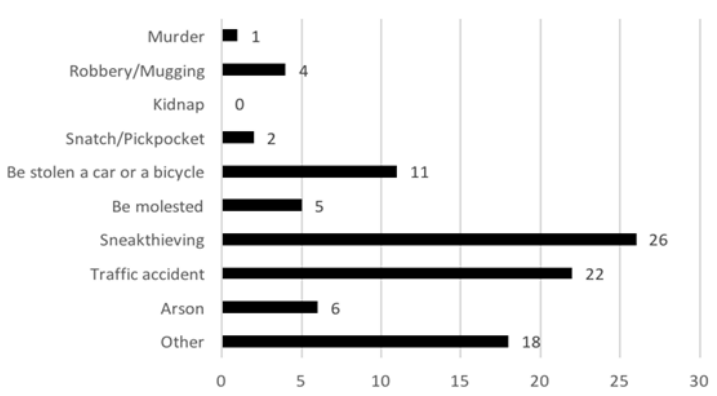

Fig. 12. The crimes they feel unsafe in their daily life.

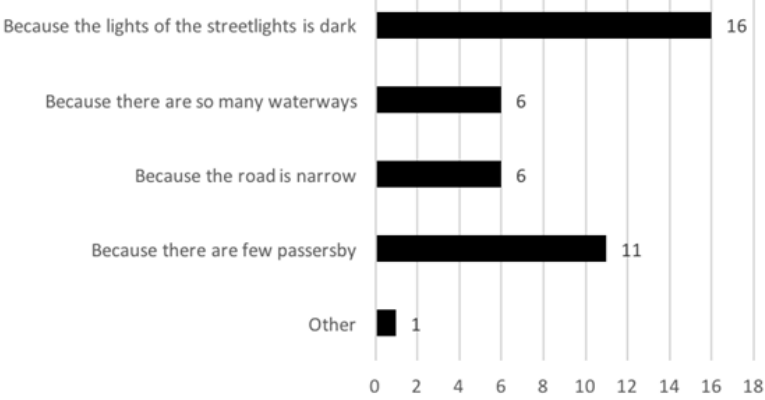

Fig. 13. The reasons why they feel hard to walk outside at night.

Third, it was about the security items or systems they are using in house or store, and many people answered they didn't install any items or systems, and security sensor lights were the second answered. Other answers included the police 
security alarms installed by Kashima city, fire alarm, automatic buzzer of door and sensor chime. The reasons for installed the security items or systems are as follows: 'Just in case.', 'Because it is dark.', 'Because I worried about the damage of crimes.', 'Because there is a step in the entrance of store, so I installed it for visitors don't get hurt.', 'I can know when visitors come.' and 'Countermeasures against burglars.'(Fig. 11).

Fourth, it was about the crimes they feel unsafe in their daily life, and they said they felt unsafe in order of sneak thieving, traffic accidents, and robbery of a car or a bicycle. Other answers included the 'nothing special', 'fraud phone call', 'when seeing a stranger', 'fire', 'theft' and 'peep' (Fig.12).

Fifth, it was about why they feel hard to walk outside at night. The reasons why they feel hard to walk are as follows: 'Because the lights of the streetlights are dark', 'Because there are few passersby', and so on (Fig.13).

\section{CONCLUSION AND FUTURE WORKS}

In this study, we could compare the results of the illumination survey and the simulation diagram with the JIS standards, and we were able to understand the current situations of streetlights in Hizenhamashuku. Based on the results of the questionnaire survey, we were able to know the residents' opinions about streetlights and crime prevention, and what they were thinking about to make this sites into a safe and secure area. There were overwhelmingly many opinions that they want the bright lights. Moreover, we need to consider not only increasing the number of streetlights to brighten up, but also matching shapes and colors of streetlights to the atmosphere of area.

As a future work, the residents' opinions about the streetlights should be considered and reflected to the security lighting plan of the target area in accordance with the residential environment maintenance project supported by Saga prefecture. Also, the procedure of measurement should be developed considering survey method of luminance of streetlights viewing from eye level.

\section{ACKNOWLEDGMENT}

This study is supported by JSPS KAKENHI Grant Number JP16H04478. We would like to thank residents in Hizen Hamashuku and all who understood and cooperated our on-site field work. We also wish to appreciate valuable discussions and comments with project members.

\section{REFERENCES}

[1] N. Mishima, N. Miyamoto, Y. Taguchi, and K. Kitagawa, "Analysis of current two-way evacuation routes based on residents' perceptions in a historic preservation area," International Journal of Disaster Risk Reduction 8, 2014, pp. 10-19

[2] T. Tanachawengsakul, N. Mishima, and T. Fuchikami, "A simulation study on fire evacuation routes in primary stage for a historic canal residential area," Procedia-Social and Behavioral Sciences 216, 2016, pp.492-502

[3] N. Srinurak, N. Mishima, T. Fuchikami, and W. Duangthima "Analysis of urban morphology and accessibility character to provide evacuation route in historic area," Procedia-Social and Behavioral Sciences 216, 2016, pp.460-469

[4] K. Painter, "The influence of street lighting improvements on crime, fear and pedestrian street use, after dark," Landscape and Urban Planning 35, 1996, pp193-201
[5] A. Peña-Garcia, A. Hurtado, and M. C. Aguilar-Luzon, "Impact of public lighting on pedestrians' perception of safety and well-being," Safety Science 78, 2015, pp.142-148

[6] A. Haans and Y. A.W. D. Kort, "Light distribution in dynamic street lighting: Two experimental studies on its effects on perceived safety, prospect, concealment, and escape," Journal of Environmental Psychology 32, 2012, pp.342-352

[7] D. Herbert and N. Davidson, "Modifying the built environment: the impact of improved street lighting," Geoforum, vol. 25 no. 3, 1994, pp. 339-350

[8] A. T. Murray and X. Feng, "Public street lighting service standard assessment and achievement," Socio-Economic Planning Sciences 53, 2016, pp.14-22

[9] D. Kim and S. Park, "Improving community street lighting using CPTED: A case study of three communities in Korea," Sustainable Cities and Society 28, 2017, pp.233-241

[10] A. S. Choi, S. J. Jang, B. C. Park, Y. O. Kim, and Y, Shik Kim, "Rational-design process and evaluation of street-lighting design for apartment complexes," Building and Environment 42, 2007, pp.3001-3013

[11] Housing and Living Environment Development Plan of Saga Prefecture, Saga Prefecture, March 2016.

[12] S. Seki. (August 1967). Progress of Illuminating Engineering up to the end of World War II from Meiji and Taisho Eras. Journal of the Illuminating Engineering Institute of Japan. [Online]. 51(8). pp. 480-493. Available: https://www.jstage.jst.go.jp/article/jieij1917/51/8/51_8_480/_article/char/ja/

[13] Road Lighting for Pedestrians, Japanese Industry Standard (JIS), JIS Z 9111, 2008

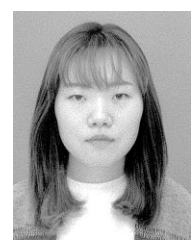

Raheon Min was born in Seoul, Korea, on October 31, 1991. She entered Saga University in April of 2013 and belonged to the department of urban engineering. She received B.E. from Saga University in 2017. She entered the Graduate School of Science and Engineering of Saga University in April 2017 as a master student.

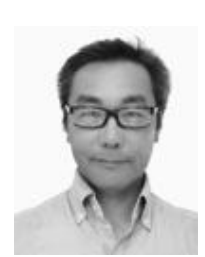

Nobuo Mishima was born in Fukuoka, Japan, on May 11 of 1964. He entered the Univ. of Tokyo in April of 1984 and belong to the department of urban engineering. He received the B.E., M.E., and D.E. degrees in urban engineering from the Univ. of Tokyo, Japan in 1988, 1990, and 1995 respectively. He also studied at Faculty of architecture and urban planning, Tech. Univ. of Vienna, Austria, as a scholarship student of Austrian government with Joint Study Program between two institutions, from October of 1990 to March of 1993.

He worked at Eto Shinchi Architecture Atelier in Vienna and in Osaka, Japan, as a Technical Staff from 1992 to 1994. Since he was graduated from the doctor course of University of Tokyo, he has been with Saga University, Japan, as Lecturer from 1995 to 1998, Assistant Professor from 1998 to 2007 , Associate Professor from 2007 to 2013, and Professor from 2013. Moreover, he got the Qualified Architect of First-class in Japan on February 7 of 1997. Prof. Dr. Arch. Mishima belongs to Arch. Inst. of Japan (AIJ), The City Planning Inst. of Japan (CPIJ), Assoc. of Urban Housing Sci. (AUHS), Japan Inst. of Archt. (JIA), Saga Archt. Assoc. (SAA), Int. Assoc. of Lowland Technology (IALT), and Korea Contents Assoc. (KoCon). His main research interests include urban planning and design, and architectural design. He has many awards from several institutions, such as two achievement awards by AUHS in 2010 and 2012, a best presentation award by the Int. Conf. of Habitat Eng. and Design in 2012, and an established fellow by Saga University in 2017. He has also many publications of books, journal papers and proceedings paper of conferences.

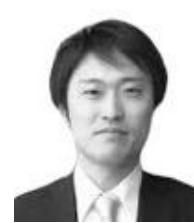

Takayuki Fuchikami was born in Saga, Japan, on October 15 of 1981. He entered the Univ. of Saga in April of 2000 and belonged to the department of civil engineering and architecture. He received the B.E. and M.E. degrees in civil engineering and architecture from the Univ. of Saga, Japan in 2004 and 2006 respectively. $\mathrm{He}$ entered the doctoral course of Saga Univ. and belonged to the department of engineering systems and technology from April of 2006 to April of 2008.

He has been with Saga University, Japan, as Assistant Professor from May of 2008. His main research interests include architectural history and design. He has also many journal papers and proceeding papers of conferences. He belongs to Arch. Inst. of Japan (AIJ). 